\title{
Treatment of Cutaneous Mucormycosis in Patients with Corticosteroid Treatment After Trauma
}

\author{
Travma Sonrasında Kortikosteroid Tedavisi Gören \\ Hastalarda Gelişen Kutanöz Mukormikoz Olgularında \\ Tedavi
}

Mustafa Kursat Evrenos

Merve Ozkaya Unsal

Department of Plastic Reconstructive and Aesthetic Surgery, Faculty of Medicine, Manisa Celal Bayar University, Manisa, Turkey

Gelis Tarihi/Received: 3 January 2019 Kabul Tarihi/Accepted: 23 February 2019

Address correspondence to: Mustafa Kursat Evrenos, Department of Plastic Reconstructive and Aesthetic Surgery, Faculty of Medicine, Manisa Celal Bayar University, Manisa, Turkey

e-mail:mkevrenos@hotmail.com

\section{ORCID}

Mustafa Kursat Evrenos

https://orcid.org/0000-0001-9784-0193

\section{INTRODUCTION}

Mucormycosis is a rare invasive fungi infection, belonging to the class of Zygomycetes(1). It is a life threatening emergency and the mortality risk is quite high(2). Several forms of disease are known due to the region of infection; pulmonary, rhino cerebral, cutaneous, gastrointestinal and disseminated $(3,4)$. This opportunistic infection generally occurs in immunocompromised individuals, especially in unregulated diabetic patients with ketoacidosis, patients with haemotological malignancies or anticancer drug using patients $(4,5)$.

Cutaneous mucormycosis is less than $\% 10$ of all of the mucoral infections(6). In the last decade, many reports of underlying cutaneous mucormycosis after major injuries or natural disasters are published(7).

Cite this article as: Evrenos MK, Unsal MO. Treatment of Cutaneous Mucormycosis in Patients with Corticosteroid Treatment After Trauma. Selcuk Med J 2019;35(2): 113-119

\footnotetext{
Disclosure: None of the authors has a financial interest in any of the products, devices, or drugs mentioned in this article. The research was not sponsored by an outside organization. All authors have agreed to allow full access to the primary data and to allow the journal to review the data if requested.
} 
These reports emphasize that the patients generally have a predisposing condition such as chronical steroid use for chronic obstructive pulmonary disease(5). Some of them have serious predisposing underlying conditions(6). There is also a report suggesting that short time use of corticosteroids (less than one month) may result in opportunistic infections in the literature, but the patient had a comorbidity of sarcoidosis(8). This is the first report of four immunocompetant patients that developed facial cutaneous mucormycosis after getting injured and given short term corticosteroids in our clinic between 2016 and 2018.

\section{PATIENTS AND METHODS}

A total of four patients who had multitrauma including intracranial, spinal and maxillofacial and received short term corticosteroid treatment and developed mucormycosis infection between Jan 2016 and Dec 2018 were included in the study. Diagnosis were confirmed with microbiological and pathological examination. Clinicopathological informations, medical and surgical treatment outcomes were evaluated.

\section{Case 1}

A 24-year-old male patient was evaluated on emergency service after an on-board traffic accident on May 2016. Debridement, open reduction internal fixation and soft tissue repair for periorbital lacerations and the open tripod fracture were performed under emergency conditions. The patient was diagnosed with cerebral diffuse axonal injury by the neurosurgery department, and methylprednisolone treatment $20 \mathrm{mg} / \mathrm{kg} 4 \times 1$ /day was given. On the 7 th day of the procedure, right periorbital cellulitis, proptosis of the right orbit, black necrosis of the skin was observed, samples for microbiology and pathology were sent (Figure 1a,b). The patient was diagnosed with fungal infection, systemic antifungal therapy was initiated immediately with liposomal amphotericin B $5 \mathrm{mg} / \mathrm{kg}$ by department of infection diseases. Wide debridement and exenteration were performed, and light colored soft necrotic fungal structures were observed (Figure 1c). The patient had optic nerve involvement, neurosurgery department did not plan surgery after consultation. Histopathology confirmed mucormycosis. The patient was observed for 45 days, and free latissimus dorsi flap operation was performed to the defect site (Fig 1d,e). The flap was lost 5 days after surgery as a result of venous congestion, and recurrence of mucormycosis was seen in the remaining tissue. One week after flap surgery, magnetic resonance imagery (MRI) of the brain showed flegmantation in masseter muscle, bilateral frontal and ethmoid sinuses and thickening of the dura. At the 200th day of hospitalization, the patient was discharged on his own request, taking recommendations of infectious diseases. The patient has been followed up for 28 months and MRI showed regression in frontal osteomyelitis and intracranial inflammatory changes. During the follow-up, as the drainage decreased, the defect site was reconstructed with split thickness skin graft (Fig 1f).

\section{Case 2}

A37 year-old patient was transferred to our emergency service after fall from height with cervical vertebra and open mandible fractures. He was hospitalized and internal fixation operations were performed for mandible fractures and soft tissue laserations. The patient was given methylprednisolon treatment for spinal trauma, on the 17 th day of hospitalization, a black necrotic wound was seen on the skin superior to upper lip which had abrasion due to trauma (Figure 2a). Samples were sent to microbiology for invasive fungal infections, which showed fungal infection and liposomal amphotericin B $5 \mathrm{mg} / \mathrm{kg}$ treatment was initiated after consulting to infectious diseases. Based on the results of face MRI, serial debridements for right malar region, temporal muscle, maxilla, zygoma and orbital wall bone resections were performed and liposomal amphotericin B treatment continued. After serial debridements, reconstruction of right malar region was performed with free osteomyocutaneous

Table 1. Clinical evaluation of the patients.

\begin{tabular}{lllll}
\hline Case & Age/Sex & Concomitant trauma & Location of mucormycosis & $\begin{array}{l}\text { Time of interval from onset of } \\
\text { symptoms to diagnose }\end{array}$ \\
\hline 1 & $24, \mathrm{M}$ & Diffuse axonal injury & Right periorbital region & 7 days \\
2 & $37, \mathrm{M}$ & Spinal fracture & Upper lip and malar region & 17 days \\
3 & $36, \mathrm{M}$ & Intracranial hemorragie & Right malar region & 10 days \\
4 & $41, \mathrm{~F}$ & Spinal fracture & Left malar region & 12 days \\
\hline
\end{tabular}


Table 2. Treatment and prognosis outcome of the patients.

\begin{tabular}{|c|c|c|c|c|}
\hline Case & Medical treatment & Surgical procedure & Reconstruction procedure & Outcome \\
\hline 1 & $\begin{array}{l}\text { Liposomal amphotericin } \\
\text { B, } 5 \mathrm{mg} / \mathrm{kg}\end{array}$ & $\begin{array}{l}\text { Right Exenteration, } \\
\text { serial debridements }\end{array}$ & $\begin{array}{l}\text { Latissimus dorsi muscle flap } \\
\text { Split thickness skin graft } \\
\text { after flap failure. }\end{array}$ & $\begin{array}{l}\text { Regression in swelling, } \\
\text { osteomyelitis continues } \\
\text { (follow-up } \\
\text { time: } 28 \text { months) }\end{array}$ \\
\hline 2 & $\begin{array}{l}\text { Liposomal amphotericin } \\
\mathrm{B}, 5 \mathrm{mg} / \mathrm{kg}\end{array}$ & $\begin{array}{l}\text { Serial wide soft } \\
\text { tissue and bone } \\
\text { debridement }\end{array}$ & $\begin{array}{l}\text { Osteocutaneous iliac } \\
\text { flap and chimeric ALT } \\
\text { flap with partial vastus } \\
\text { medialis muscle }\end{array}$ & $\begin{array}{l}\text { Disease-free, } \\
21 \text { months }\end{array}$ \\
\hline 3 & $\begin{array}{l}\text { Liposomal amphotericin } \\
\text { B, } 5 \mathrm{mg} / \mathrm{kg}\end{array}$ & $\begin{array}{l}\text { Serial wide soft } \\
\text { tissue debridement }\end{array}$ & $\begin{array}{l}\text { Local flap } \\
\text { Local flap }\end{array}$ & $\begin{array}{l}\text { Disease-free } \\
\text { (8 months) }\end{array}$ \\
\hline 4 & $\begin{array}{l}\text { Liposomal amphotericin } \\
\text { B, } 5 \mathrm{mg} / \mathrm{kg}\end{array}$ & $\begin{array}{l}\text { Wide soft tissue } \\
\text { debridement }\end{array}$ & & $\begin{array}{l}\text { Disease-free } \\
\text { (11 months) }\end{array}$ \\
\hline
\end{tabular}

iliac flap and upper lip defect reconstructed with chimeric Anterolateral thigh flap. Flap revisions were performed for optimal functional and aesthetic outcomes (Figure 2b-h).

\section{RESULTS}

Three of the patients were male. Age of the patients ranged between 24 and 41 (mean:34.5). All of the patients had high energy trauma a result of motorcycle accident or falling from height and had concomittant
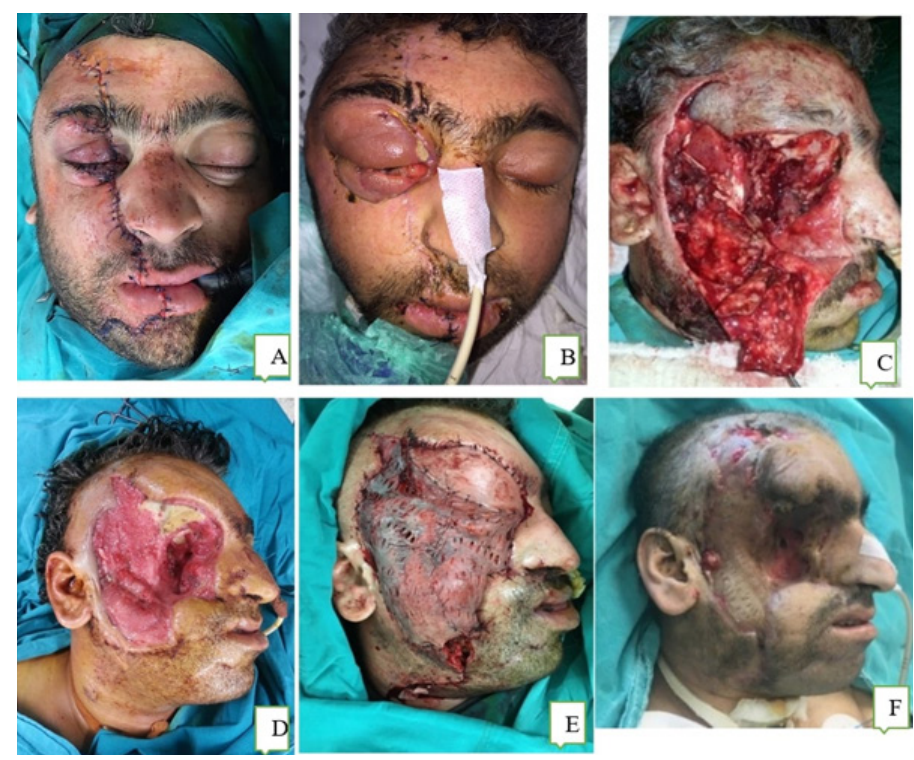

Figure 1. A) View of the case 1 at the end of maxillofacial trauma operation. B) Right periorbital edema, swelling and proptosis. C) Light coloured fungal infections observed during wide debridement and exenteration. D) View of the defect before reconstruction with latissimus dorsi free muscle flap. E) Reconstruction of the defect with latissimus dorsi free muscle flap. F) View of the patient 28 months after trauma. Reconstruction surgery will be planned after regression of frontal osteomyelitis and dural inflammation. maxillofacial trauma including displaced bone fracture and contaminated soft tissue injury (Table 1). Patients were operated for maxillofacial fractures and soft tissue lacerations. All patients received $20 \mathrm{mg} / \mathrm{kg} /$ day methylprednisolon treatment for brain or spinal nerve decompression. Lesions were seen clinically between 7 and 17 days after injury (mean:11.5). Serial debridements were performed until negativity of histopathological evaluation and radiological imaging with MRI for the patients 2-4. Follow-up period ranged between 8 and 28 months (mean:17). Three patients are disease free with acceptable functional and aesthetic results (Table 2). The first patient is being
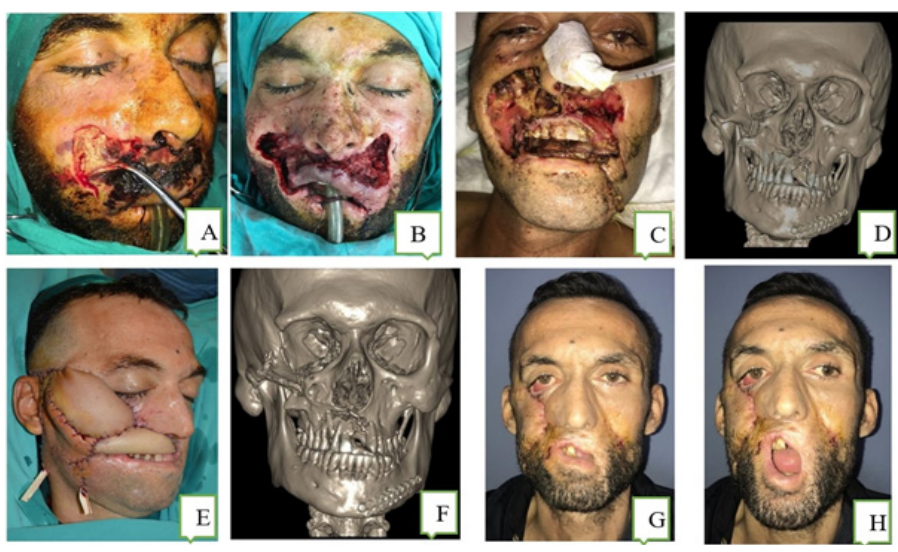

Figure 2. A) Black necrotic tissue located above upper lip. Light colored fungi infection seen beneath the incision. B) View of the patient after the first debridement. C) Debridement, 3 months after diagnosis. D) Bony defecet at right malar region of the patient after last debridement. E) Intraoperative view of the patient after defect reconstructions with free flap surgery. F) View of the iliac flap bone at right orbit floor 13 months after flap surgery. G) View of the patient 21 months after trauma. H) Acceptible functional outcome of the oral spinchter is seen. 
evaluated for further reconstruction options.

\section{DISCUSSION}

Mucormycosis is a rare invasive fungi infection, belonging to the class of Zygomycetes. As it is known that there are two types of fungal infections, opportunistic and pathogenic, mucormycosis is one of the opportunistic pathogens which is less common than Candida and Aspergillus spp $(1,9)$. In the first instance, in 1885, Platauf published his paper named "Mycosis Mucorina"(10). Until now, most of the infections are diagnosed after tissue morphology, but is rarely confirmed by culture of fungi. It is common that once the morphologic tissue finding show the angioinvasive hyphae, the infection is identified as "mucormycosis" without the culture(11). The agents that causes the disease zygomycoses belong to the class Zygomycetes, which includes the orders Mucorales and Entomophthorales(9). The order Entomophthorales produce a chronic subcutaneous infection called entomophthoramycosis(3). This infection generally causes subcutaneous and mucocutaneous infections in immunocompetent patients, and usually seen in tropical and subtropical climates $(3,9)$. Traditionally, the order of Mucorales contains six families that cause disease in humans or animals: Mucoraceae, , Saksenaea, Cunninghamellaceae, Thamnidiaceae, Mortierellaceae and Syncephalastraceae (11). Species belonging to the family Mucoraceae are the most frequently isolated form in all these families. Rhizopus oryzae is found to be the most common cause of infections among the Mucoraceae family $(9,11)$.

The fungi can be found in soil, environment, even in the air $(12,13)$. Contaminated wounds after traffic accidents, natural disasters and also scratches caused by trees or farm products are reported in literature(1,14-16). In 1984, Diamond et al. (17) have shown that mononuclear and polymorphonuclear cells can kill the tissue invasive hyphal phase of Rhizopus oryzae. Now, it is known that phagocytes are the main defence mechanism for mucormycosis(9). In immuncompetant hosts, the main defence is initiated by macrophages in two ways; phagocytosis and oxidative mechanisms(11). If the host has a dysfunction in this mechanism, the risk of mucormycosis infection increases(9). It is mainly confined to patients receiving long-term antibiotics, with irregular diabetes or immunosuppressive patients(13). Neutropenic patients are vulnerable for mucormycosis due to decreased number of phagocytes. The function of phagocytes may also be impaired due to hyperglycemia and acidosis. Therefore, diabetic ketoasidosis, predisposes this fungal infection. Corticosteroids is a pharmacological immunosupression model by causing dysfunctional neutrophils $(9,11,18)$. Also burns, hematological malignancies, viruses causing immunodeficiency (i.e. AIDS) and anti-cancer agents are known risk factors $(4,5,13,19)$. According to a population-based study, 1.7 cases per million people/year is estimated to develop mucomycosis(9). Over the last two decades, as the incidence of cancer, numbers of organ transplantation, treatments with immunsuppressive agents patients with immunosuppressive diseases rise, a remarkable increase is seen in reported cases of mucormycosis $(9,20)$.

There are differences between the epidemiology of mucor between developed and developing countries(4). The disease is uncommon in developed countries, and the majority of patients are the patients with diabetes, hematological malignancies receiving chemotherapy and especially patients who have received allogeneic stem cell transplants(9). In developing countries, this fungal infection is generally seen in patients with irregulated diabetes mellitus or after trauma $(3,21)$. Mucormycosis commonly presents in five forms: pulmonary, rhinocerebral, gastrointestinal, cutaneous, and disseminated $(3,4)$. Clinical manifestation may vary due to exposure form. There are three major ways to enter the human body; via inhalation, percutaneous transition or ingestion(3,11,22). The most common type of mucormycosis is rhino-cerebral form in most series $(21,23)$. If the fungus is located in the paranasal sinuses via inhalation of spores and these spores diffuse to the nearby structures (like the orbit or the brain) it is possible for intracranial extension and risk of mortality increases(24).Cutaneous mucormycosis is one of the most common forms.(3). Skin lacerations or nonspesific skin injuries may also be a portal for fungal infection(25). These cases usually occur in immunocompromised patients or the patients with predisposant factors(26). But also cutaneous forms have been reported in traumatic immunocompetant patients over the past years $(1,16,27)$. Primary cutaneous mucormycosis without trauma is very rare, and mortality risk is high(28). Also bone marrow necrosis and osteomyelitis have been reported due to mucormycosis(29).

The most common risk factors were diabetes 
and leukemia/neutropenia(30). Adam et al.(30) compared the patients with forms of mucormycosis and comorbidities. They reported that cutaneous mucormycosis is less frequently associated with systemic illnesses than other forms. Also the mortality of cutaneous form is less than rhinocerebral, disseminated or pulmonary mucormycosis.

It is known that type of the form of mucormycosis has a relationship with predisposing factors(9). While a patient with diabetic acidosis has a tendency to develop rhinocerebral mucor, a neutropenic patient is more likely to develop pulmonary or disseminated infections. Corticosteroids is believed to result in pulmonary, disseminated or rhinocerebral form, but in our study all of our patients using corticosteroids had cutaneous mucor on traumatic regions(9). Mucormycosis in immunocompetent patients usually being related to trauma have also been reported $(12,16)$. On the other hand, sometimes it results from occult immune abnormality as in published cases of Gonzales-Ballester et al. (22), where two patients without known risk factors developed mucormycosis on facial areas. There are many other cases which reports immunocompetant patients developing cutaneous mucormycosis after contamination with soil(12,15,28,31-33). In a study in literature including 7 patients with mucor infections in upper extremities, it was reported that 3 infections were caused by soil contamination due to traffic accident and 4 patients were injured by farm equipment or conveyor belt in an agricultural environment(12). They reported that none of their patients had an systemic illness before trauma, like in our study(12). Gordon et al. (32) published an 11 years old case report which was injured by a farm machine and having no immunocompromising predisposition. Likewise, a case of mucormycosis due to a lemon-tree-thorn scratch was published by Petrikkos et al. (15)

Cutaneous mucormycosis is less than $\% 10$ of all of the mucoral infections(6). Burns, traumatic minor lacerations on skin and chronic maceration of skin may resul in the fungi to transport into deeper tissues(9). In a study from Greece, two cutaneous mucormycosis patients was reported which had no predisposing factors after traffic accident. They also reported that in anamneses of one of these patients, few months earlier her brother was hospitalized in another center for treatment of mucor infection, and she had a history of pruritus and scratching her scar before injury. Petrikkos et al. (15) presumed this was the way of transmission. In a study that compares cutaneous mucormycosis to the four series published in the literature that included at least 10 patients with other forms of infections in 1994, they found that \%16 of patients had cutaneous form of mucor in 116 patients published in literature with all forms of mucormycosis. They also reported mortality rate of cutaneous mucormycosis was \%16(30).

Primary cutaneous mucormycosis due to chronic use of corticosteroids is reported(6). Also in literature, a case with sarcoidosis is reported to develop mucor infection(8). They suggested that even if the patient uses corticosteroids shorter than one month, it may be a risk factor for mucormycosis. Another patient with diabetes mellitus was reported to have rhinoserebral mucormycosis after two weeks of high-dose steroid therapy for chronic obstructive pulmonary disease(5). They also reported that after treatment, irregulated glucose levels and acidosis due to low creatin clearance may have triggered this infection. Four cases we report were given corticosteroid treatment, all of their blood glucose levels were under $180 \mathrm{mg} / \mathrm{dL}$ and blood $\mathrm{pH}$ was in normal limits, yet had a tendency for alcalosis $(\mathrm{pH}>7.40)$.

Mucormycosis causes thrombosis, infarction, and tissue necrosis by vascular invasion $(9,31)$. The black necrotic eschar is a remarkable finding in cutaneous mucormycosis(15). In our patients, all of them had black necrotic tissue on the site of injury, which were misdiagnosed as a basic non healing and ischemic wound. After repetitive biopsies and bacterial cultures, fungi were diagnosed. A frozen section pathology resulted in definitive and rapid diagnosis. Iron overload, whether caused by dyserythropoiesis, frequently transfusion or deferoxamine therapy, is found to be a risk factor for zygomycosis(34). Elevated serum iron is a recently identified significant clinical feature and it is used by the fungi as a growth factor and improve the pathogenity $(9,11,34)$. In patient two, after diagnosis, the oral iron supplementation therapy given for anemia which was considered to occur due to frequent operations and antibiotics that cause bone-marrow suppression, was stopped.

Generally osteomyelitis tend to occur after rhinocerebral mucormycosis, especially in maxillary bones and scull base(29,35-37). All of these patients also have comorbidities, mostly diabetes and lymphoma. Mucormycosis of frontal sinus in a patient with diabetes and renal insufficiency is also reported(38). However in our case, cutaneous mucormycosis caused osteomyelitis of maxillary, zygomatic and frontal bones. Treatment options 
include aggressive surgical debridement, antifungal therapy (amphotericin B), glucose regulation, hyperbaric oxygen and combinations of these therapies evaluating the patient $(9,32,39)$. Rapidly and extensive surgical debridement is strictly suggested(15,32). Treatment algorithm suggested by Moran et al. (12) includes aggressive surgical debridement and concomittant tissue biopsy examination and cultures, systemic antifungal therapy, repetitive and wide surgical debridement of the necrotic tissues. In literature, in most cases it was necessary to repeat the debridement(15,28,32). Gordon et al. (32) suggested that repeating debridement in every $12-24$ hours as needed depending on the progress of the infection. All of our cases were treated with serial debridements, for about 15 days to 8 months until the pathology report was clear. Prognosis of mucormycosis was evaluated with MRI. Cure was confirmed after pathological evaluation.

\section{CONCLUSION}

Mucormycosis is a low-virulent opportunistic fungal infection that is frequently exposed in daily life. The incidence is increasing in proportion to the increase in cancer, organ transplantation and immunosuppressive agent use in recent years. It has been reported that rarely, immunocompetent individuals develop mucormycosis after major disasters, burns and major dirty traumas. It is important to consider the possibility of mucormycosis when a spontaneous or unexpected necrotic soft tissue infection presents. Frozen section of samples is recommended for definitive and rapid diagnosis. It is considered that the corticosteroid treatment that was given may have induced the development of cutaneous mucormycosis after contamination with soil during trauma, because of the absence of known additional diseases before trauma. Mucormycosis should be kept in mind in resistant wound infections in patients who have been treated with corticosteroids even for a short time after cranial or spinal trauma. Rapid, repetitive and aggressive debridemants should be performed, and reconstruction should be delayed after disease free surgical margins are achieved.

Conflict of interest: Authors declare that there is no conflict ofinterest between the authors of the article.

Financial conflict of interest: Authors declare that they did notreceive any financial support in this study.
Address correspondence to: Mustafa Kursat Evrenos, Department of Plastic Reconstructive and Aesthetic Surgery, Faculty of Medicine, Manisa Celal Bayar University, Manisa, 45010, Turkey

Phone: +90 5054960857 Fax: +902362370330

e-mail: mkevrenos@hotmail.com

\section{REFERENCES}

1. Kyriopoulos EJ, Kyriakopoulos A, Karonidis A, et al. Burn injuries and soft tissue traumas complicated by mucormycosis infection: A report of six cases and review of the literature. Ann Burns Fire Disasters 2015;28(4):280-7.

2. Roden MM, Zaoutis TE, Buchanan WL, et al. Epidemiology and outcome of zygomycosis: A Review of 929 Reported Cases. Clin Infect Dis 2005;41(5):634-53.

3. Prabhu RM, Patel R. Mucormycosis and entomophthoramycosis: A review of the clinical manifestation, diagnosis and treatment. Clin Microbiol Infect 2004;10 Suppl.:31-47.

4. Petrikkos G, Skiada A, Lortholary O, et al. Epidemiology and clinical manifestations of mucormycosis. Clin Infect Dis 2012;54(SUPPL. 1):23-34.

5. Ferguson $A$. Rhinocerebral mucormycosis acquired after a short course of prednisone therapy. JAOA J Am Osteopath Assoc 2007;107(11):491-3.

6. Losee JE, Selber J, Vega S, et al. Primary cutaneous mucormycosis: Guide to surgical management. Ann Plast Surg 2002;49(4):385-90.

7. Benedict K, Park BJ. Invasive fungal infections after natural disasters. Emerg Infect Dis 2014;20(3):349-55.

8. Alloway J, Buchsbaum R, Filipov P, et al. Mucormycosis in a patient with sarcoidosis. Sarcoidosis 1995;12(2):143-6.

9. Spellberg B, John Edwards J, Ibrahim A. Novel perspectives on mucormycosis: Pathophysiology, presentation, and management. Clin Microbiol Rev 2005;18(3):556-69.

10. Platauf A. Mycosis mucorina. Virchows Arch. 1885;102:54364.

11. Ribes JA, Vanover-Sams CL, Baker DJ. Zygomycetes in human disease. Clin Microbiol Rev 2000;13(2):236-301.

12. Moran SL, Strickland J, Shin AY. Upper-extremity mucormycosis infections in immunocompetent patients. Hand Surg 2006;31(7):1201-5.

13. Mizutari K, Nishimoto K, Ono T. Cutaneous mucormycosis. J Dermatol 1999;26:174-7.

14. Koldas K, Solgun G, Deveci A, et al. A Case of cutaneous mucormycosis developing after a traffic accident. Klimik Dergisi/Klimik J 2015;27(1):33-5.

15. Petrikkos G, Skiada A, Sambatakou H, et al. Mucormycosis: Ten-year experience at a tertiary-care center in greece. Eur J Clin Microbiol Infect Dis 2003;22(12):753-6.

16. Kontogiorgi M, Floros I, Koroneos A, et al. Fatal post-traumatic zygomycosis in an immunocompetent young patient. J Med Microbiol 2007;56(9):1243-5.

17. WaldorfAR, Ruderman N, Diamond RD. Specific susceptibility to mucormycosis in murine diabetes and bronchoalveolar macrophage defense against Rhizopus. J Clin Invest 1984;74(1):150-60.

18. Baddley JW, Stroud TP, Salzman D, et al. Invasive mold infections in allogeneic bone marrow transplant recipients. Clin Infect Dis 2001;32(9):1319-24.

19. Kaushik R. Primary cutaneous zygomycosis in India. Indian J 
Surg 2012;74(6):468-75

20. Gleissner B, Schilling A, Anagnostopolous I, et al. Improved outcome of zygomycosis in patients with hematological diseases? Leuk Lymphoma 2004;45(7):1351-60.

21. Chakrabarti A, Sakhuja V. Ten years' experience in zygomycosis at a tertiary care centre in India. J Infect. 2001;42(4):261-6.

22. González Ballester D, González-García R, Moreno García C, et al. Mucormycosis of the head and neck: Report of five cases with different presentations. J Cranio-Maxillofacial Surg 2012;40(7):584-91.

23. Parfrey N. Improved diagnosis and prognosis of mucormycosis. A clinicopathologic study of 33 cases. Med (Baltimore) 1986;65(2):113-23.

24. Mohindra S, Mohindra S, Gupta R, et al. Rhinocerebral mucormycosis: The disease spectrum in 27 patients. Mycoses 2007;50(4):290-6.

25. Leitner C, Hoffmann J, Zerfowski M, et al. Mucormycosis: Necrotizing soft tissue lesion of the face. J Oral Maxillofac Surg 2003;61(11):1354-8.

26. Dhiwakar M, Thakar A, Bahadur S. Improving outcomes in rhinocerebral mucormycosis - Early diagnostic pointers and prognostic factors. J Laryngol Otol 2003;117(11):861-5.

27. Mignogna MD, Fortuna G, Leuci S, et al. Mucormycosis in immunocompetent patients: A case-series of patients with maxillary sinus involvement and a critical review of the literature. Int J Infect Dis 2011;15(8):e533-40.

28. Kumar A, Khilnani G, Aggarwal S, et al. Primary cutaneous mucormycosis in an immunocompetent host: Report of a case. Surg Today 2003;33:319-22.

29. Meyer R, Armstrong D. Mucormycosis-changing status. CRC Crit Rev Clin Lab Sci 1973;4:421-51.

30. Adam RD, Glenn H, Di Tomasso J, et al. Mucormycosis: Emerging prominence of cutaneous infections. Clin Infect Dis 1994;19(1):67-76.
31. Mata-Essayag S, Magaldi S, Hartung de Capriles C, et al. Mucor indicus necrotizing fasciitis. Int $\mathrm{J}$ Dermatol 2001;40:406-8.

32. Gordon G, Indeck M, Bross J, et al. Injury from silage wagon accident complicated by mucormycosis. J Trauma 1988;28(6):866-7.

33. El Deeb Y, Al Soub H, Almaslamani M, et al. Post-traumatic cutaneous mucormycosis in an immunocompetent patient. Ann Saudi Med 2005;25(4):343-5.

34. Chayakulkeeree M, Ghannoum MA, Perfect JR. Zygomycosis: The re-emerging fungal infection. Eur J Clin Microbiol Infect Dis 2006;25(4):215-29.

35. Selvamani M, Donoghue M, Bharani S, et al. Mucormycosis causing maxillary osteomyelitis. J Nat Sci Biol Med 2015;6(2):456-9.

36. Auluck A. Maxillary necrosis by mucormycosis. A case report and literature review. Med Oral Patol Oral Cir Bucal 2007;12(5):360-4.

37. Chan LL, Singh S, Jones D, et al. Imaging of mucormycosis skull base osteomyelitis. Am J Neuroradiol 2000;21(5):82831.

38. Sahoo N, Kulkarni V, Bhandari A, et al. Mucormycosis of the frontal sinus: A rare case report and review. Ann Maxillofac Surg 2017;(7):120-3.

39. Rippon J. Medical Mycology: The pathogenic fungi and the pathogenic actinomycetes. In: Medical mycology: The pathogenic fungi and the pathogenic actinomycetes. Philedelphia, Saunders;1982. p. 615-40. 